\title{
NOTAS
}

\section{ZONAS DIALECTALES DE TABASCO Y VERACRUZ ESTUDIO LÉXICO}

Juan M. Lope Blanch ${ }^{1}$ ha hecho hincapié en algunas correcciones o matizaciones que merecen hacerse a la clásica división del español mexicano propuesta por $\mathbf{P}$. Henríquez Ureña ${ }^{2}$, en lo referente a la inclusión de los estados de Campeche y Tabasco dentro de la modalidad lingüística propia de la costa del Golfo de México; ha mostrado también la conveniencia de incluir por lo menos al estado de Campeche -e inclusive, en algunos casos, a la costa oeste de Tabasco- en la zona yucateca. Para llegar a estas conclusiones, Lope Blanch utilizó veinticinco conceptos que muestran claramente el carácter yucateco predominante en las variantes léxicas obtenidas en el estado de Campeche y parte de Tabasco. Me parece que es de interés determinar con mayor precisión el carácter dialectalmente fronterizo del estado de Tabasco, y ver si se inclina hacia la modalidad yucateco-campechana o hacia la veracruzana. Siguiendo la línea trazada por Lope Blanch, creo conveniente extender la investigación al estado de Veracruz, tanto para observar la relación que con él establece la modalidad tabasqueña, cuanto para estudiar la posibilidad de dividir en zonas el extenso territorio veracruzano.

Para que este estudio sea una continuación de $L Z M$, he partido de los mismos conceptos, reduciéndolos a diecinueve ${ }^{3}$. En los mapas se incluyen las respuestas de varios informantes por localidad (cf. $L Z M$, p. 3, nota 7) Io que representa un mayor margen de seguridad en los resultados. Esto conlleva también un problema: la dificultad de establecer isoglosas nítidas. Creo que si hay poliformismo a nivel fonético ${ }^{4}$, puede existir, en menor escala, este fenómeno a nivel léxico; de ahí concluimos que las zonas que intento delimitar no pueden ser identificables siempre con toda nitidez. El mapa 1 contiene las localidades en que se realizaron encuestas. El orden de los mapas es el mismo de LZM, con las omisiones señaladas en la nota 3 , es decir, obedece al siguiente criterio:

1 "El léxico de la zona maya en el marco de la dialectologia mexicana", $N R F H$, 20 (1971), 1-63. En adelante LZM.

2 "Observaciones sobre el español de América", RFE, 8 (1921), 357-390.

3 Omito aqui los siguientes conceptos: 'luciérnaga', 'ńiño recién nacido', 'horquilla para el pelo', 'saltar a la cuerda', 'enhebrar' y 'tirabuzón', que presentaron pocas variantes en la zona estudiada.

4 Véase Manuel Alvar, "Polimorfismo y otros aspectos fonéticos en el habla de Santo Tomás Ajusco", $A L M, 6$ (1966-67), 11-42. 
1) denominaciones de base indígena ('Benjamín, el hijo menor') ; 2) denominaciones de base indígena frente a designaciones hispánicas ('migas de pan', 'orzuelo, divieso') ; 3) denominaciones de base indígena frente a otras designaciones indígenas o hispánicas ('leporino', 'posos, sedimentos de los líquidos') ; 4) denominaciones de base hispánica frente a denominaciones indígenas ('pavo') ; 5) base hispánica frente a bases indígenas o hispánicas ('papalote, cometa', 'voltereta') ; 6) bases hispánicas diversas ('monedas sueltas', 'adehala', 'raya del pelo', 'colibrí', 'armónica', 'tirador', 'desportillar', 'hilo', 'coser', 'horquilla plana, pasador', 'bíceps').

En los mapas de $L Z M$ aparecen las designaciones o variantes de los conceptos en toda la República con el objeto de oponer la zona yucateca a las demás del país. Aquí intento acercarme a una zona en particular (Tabasco y Veracruz). Es natural, pues, que no siempre las delimitaciones que resultan en mis mapas correspondan con absoluta exactitud a la distribución de las variantes en los mapas de $L Z M$, debido a su carácter general en oposición a los detalles que doy en estos mapas.

\section{OBSERVACTONES A LOS MAPAS}

Mapa 1. Denominación de las localidades. De las veintiséis localidades que seleccioné, hay siete que geográficamente no pertenecen al estado de Veracruz. Sin embargo, creo que es conveniente tomarlas en cuenta porque, como es obvio, las fronteras políticas no corresponden necesaria-

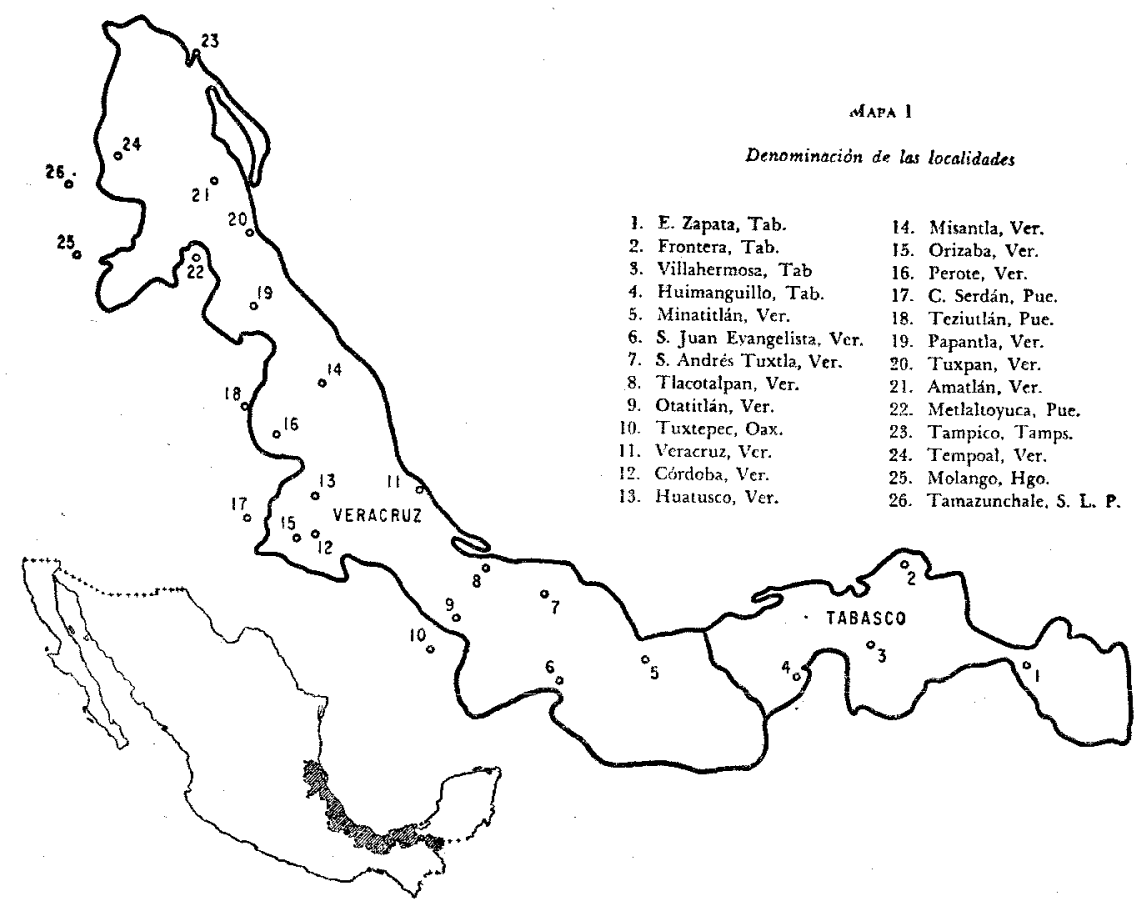


mente a isoglosas lingüísticas. En todo caso, a lo largo del estudio podrá comprobarse si estos puntos pertenecen o no, lingüísticamente, al estado de Veracruz. Convencionalmente me referiré a Veracruz como la zona señalada por los puntos 5 a 26 y a Tabasco como la zona que comprende los puntos 1 a 4 . La interpretación de los datos, por razones descriptivas, la presento en un marco político (Veracruz, Tabasco) pero de ninguna manera quiero referirme con ello a dialectos preestablecidos. No tomé localidades fronterizas del sur de Veracruz (estado de Oaxaca) ni del sur de Tabasco (estado de Chiapas) porque se trata de regiones muy poco pobladas.

Mapa 2. 'Benjamín, el hijo menor' ( $L Z M, 2)^{5}$. TABAsco: la distribución de las variantes muestra un alto grado de polimorfismo. Una de las designaciones correspondientes a la zona yucateca, suto ${ }^{6}$, sólo aparece en cuatro de las trece respuestas; sin embargo, es la más frecuente dado que las demás aparecen tres, dos o una vez únicamente. En este mapa el estado de Tabasco muestra una sola zona notablemente polimórfica.-

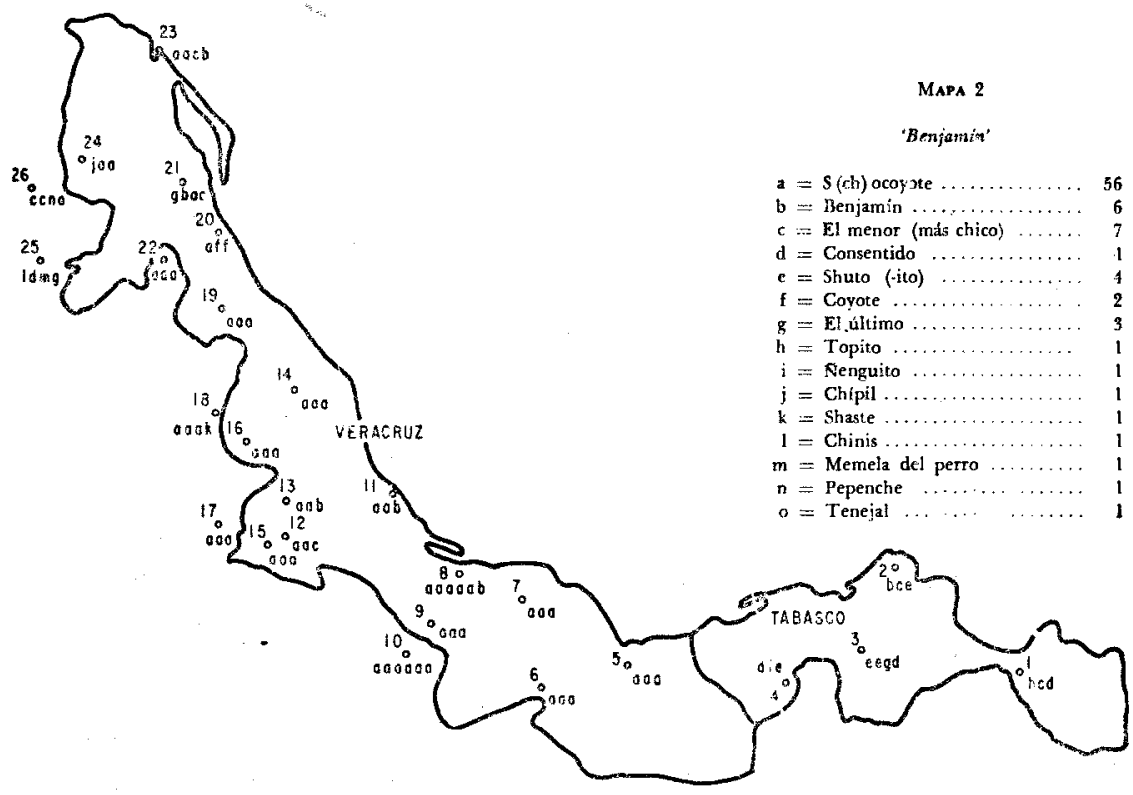

VERACRUZ: El grado de polimorfismo de las variantes se reduce notablemente. Hay un abrumador predominio de la voz s(ch)ocoyote. En ocho de las quince localidades pertenecientes a Veracruz fue respuesta única. Las demás voces deben interpretarse como esporádicas, sobre todo porque ninguna de ellas registra frecuencia considerable en ninguna zona o punto particular. Puede, por tanto, considerarse que, en cuanto a este concepto, el estado de Veracruz forma una zona dialectal. Es interediente.

El número que aparece al lado de $L Z M$ hace referencia al mapa correspon- 
sante observar que en los puntos 25 y 26, que no pertenecen geográficamente a Veracruz, no se documentó con ningún informante la voz s(ch)ocoyote.

Mapa 3. 'Migas de pan' ( $L Z M, 3)$. TABasco: de trece respuestas, ocho correspoden a la denominación yucateca šis y cuatro a la genérica migajas, extendida por varias regiones de Veracruz en particular y de la República en general. El estado puede interpretarse como una sola zona polimórfica, con evidente preponderancia de $s i s$, voz que no se oye en Veracruz. - VerAcruz: No hay división clara de zonas. Sin embargo, pueden apreciarse cinco regiones no nítidamente diferenciadas: a) 5: boronas; b) 6 y 7: migajas; c) 8 a 10: menuzas; d) 11 a 20: migajas; e) 21 a 26: absoluto polimorfismo.

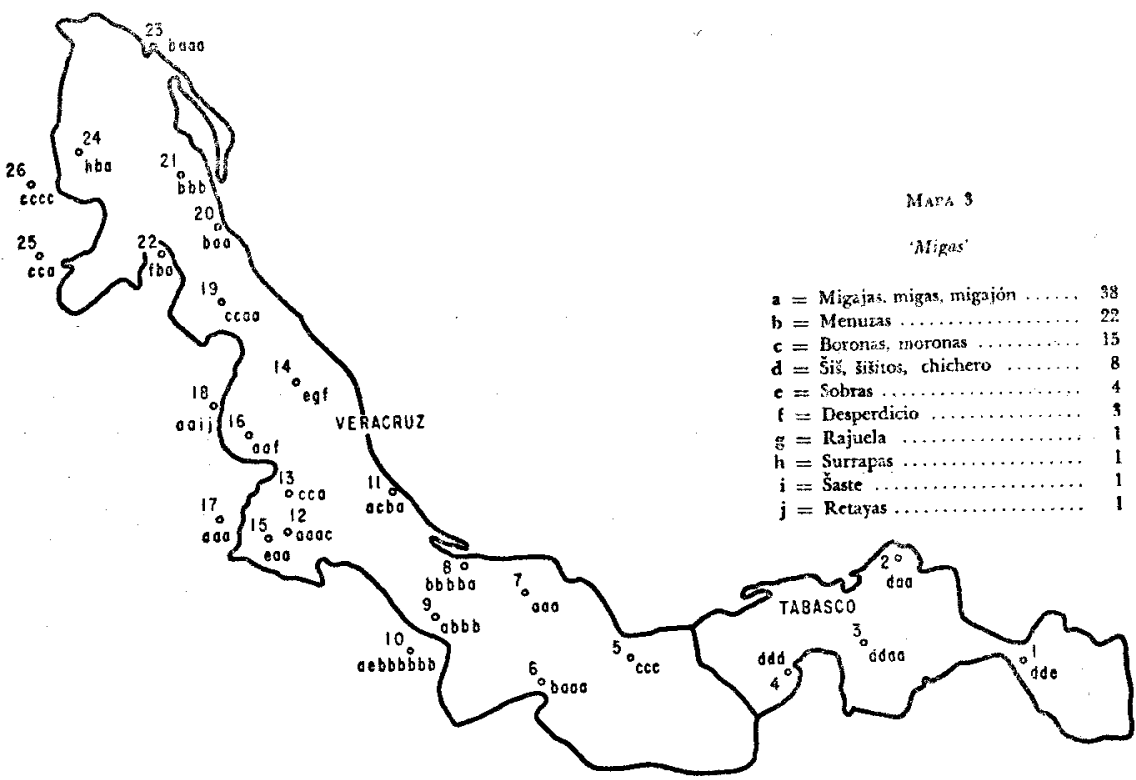

Mapa 4. 'Orzuelo, divieso' (LZM, 4). TABAsco: de trece respuestas, once corresponden al término yucateco tutupiche, no documentado en Veracruz, y sólo una a perrilla, voz uniforme en Veracruz y en la República. De cuatro informantes uno contestó chipipita, respuesta no escuchada en ninguna otra parte. El estado representa una sola zona de gran uniformidad en tutupiche. - VERACRUz: Todo el estado es una sola zona bastante homogénea con la voz perrilla. Hubo respuestas uniformes en dieciocho de las veintidós localidades; obsérvese, sin embargo, que en 20 ningún informante usó el término perrilla.

6 Debido a que en $L Z M$ se dan detalladamente las posibles etimologías de la gran mayoriá de las voces que aparecen en mi trabajo, no me detendré en ello. En la parte final de $L Z M$ se encuentra un indice completo de las voces, que remite al lugar de la explicación. 


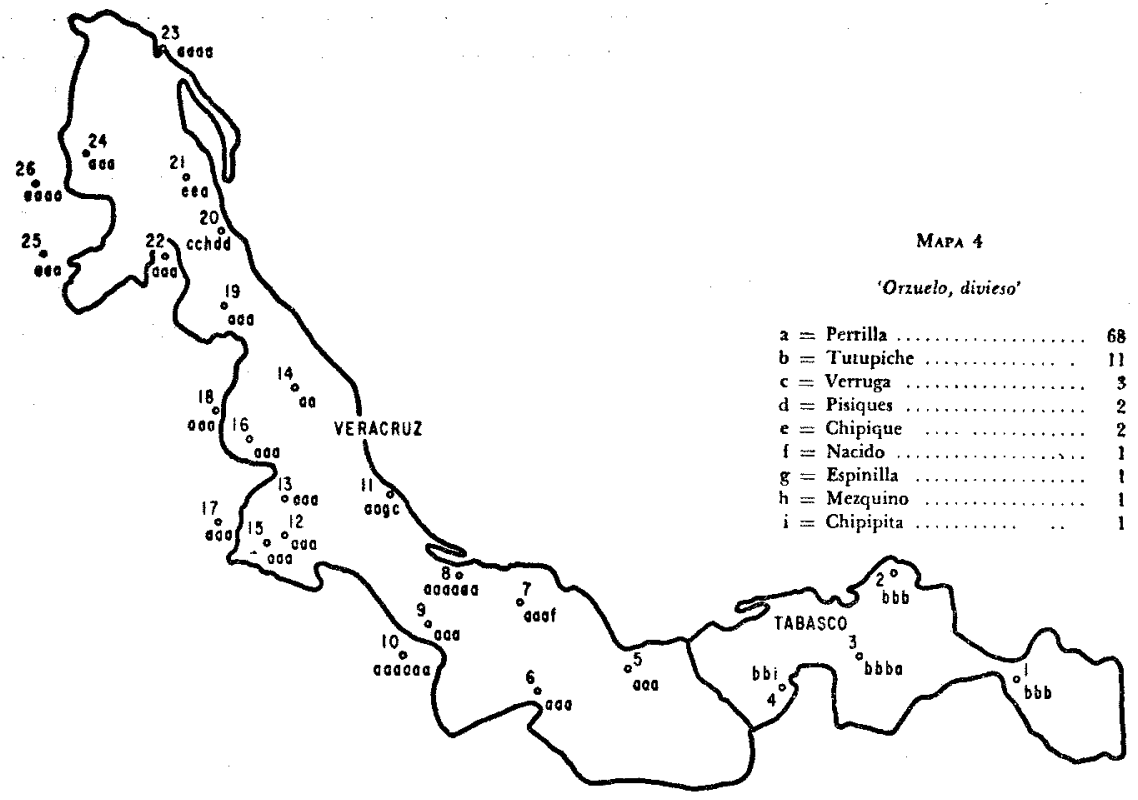

Mapa 5. 'Leporino' ( $L Z M, 5)$. El mapa muestra una distribución muy compleja de las variantes, por otra parte muy abundantes, del concepto 'Ieporino'. Tabasco: Hay que señalar que sólo 1 se anexa al dialecto yucateco con respuesta sete, que no entra a Veracruz; 2,3 y 4 se inclinan hacia el polimórfico dialecto veracruzano, aunque no con la variante más frecuente allí (tencua) sino con comido de luna, que se registró de

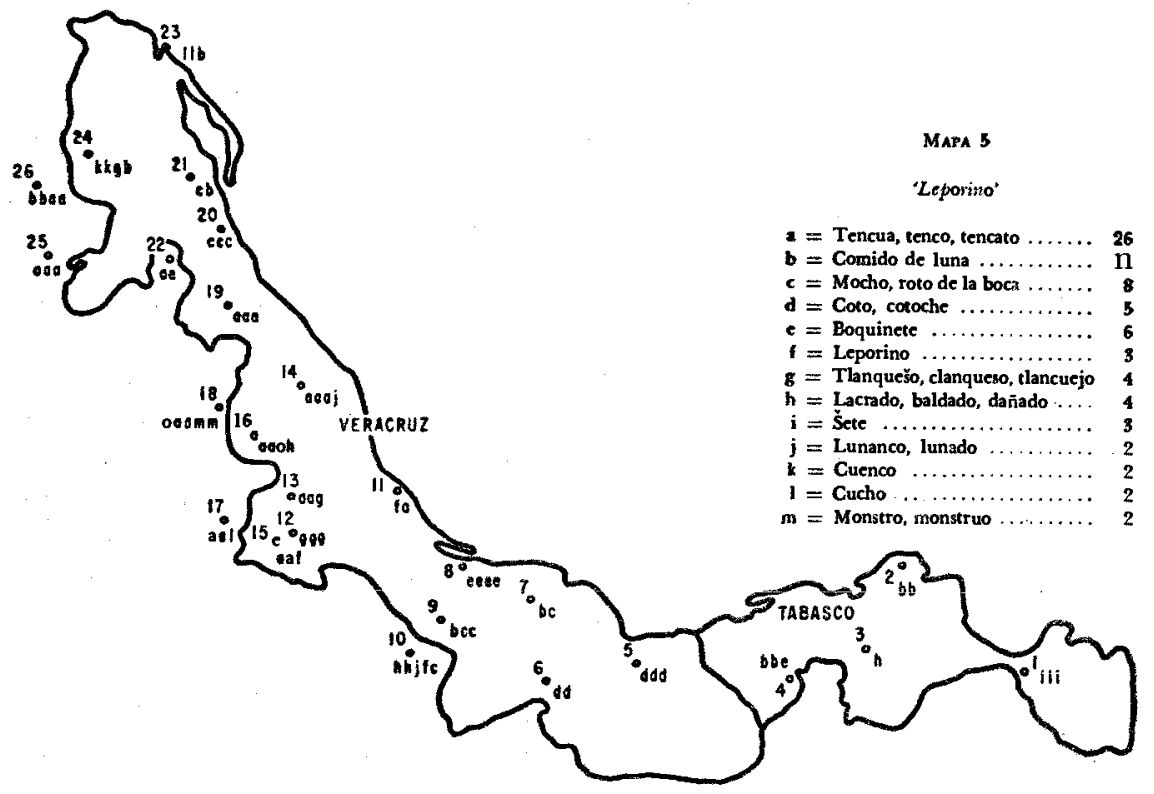


manera muy dispersa en siete ocasiones en Veracruz. - Veracruz: Con mucha dificultad puede encontrarse alguna zona de respuestas más o menos homogéneas. En sólo ocho de las veintidós localidades hubo respuesta uniforme. Puede tal vez aceptarse como zona la que contiene las localidades 12 a 19, en que predomina notablemente la variante tencua; otra posible zona es la señalada por 5 y 6 con respuesta uniforme coto(che). Es notable el caso de 8 con respuesta uniforme boquinete que sólo apareció una vez más en 4 . En los demás puntos se observa un notable poliformismo.

Mapa 6. 'Posos, sedimentos de los líquidos' ( $L Z M, 7)$. Tabasco: de un total de trece respuestas, once corresponden al término yucateco šiš, que prácticamente no se conoce en Veracruz, pues sólo un informante de 5 dio esa respuesta. Sólo dos veces apareció el genérico asientos, documentado en Veracruz y en la mayor parte del país. El estado constituye una sola zona uniforme en šis. - Veracruz: Pueden determinarse con bastante nitidez cuatro zonas; a) 5 a 10 : chancaste; b) 11 a 17: asientos; c) 14 a 18: chancaste; d) 19 a 26: asientos. Las zonas c) y d) son de absoluta uniformidad.

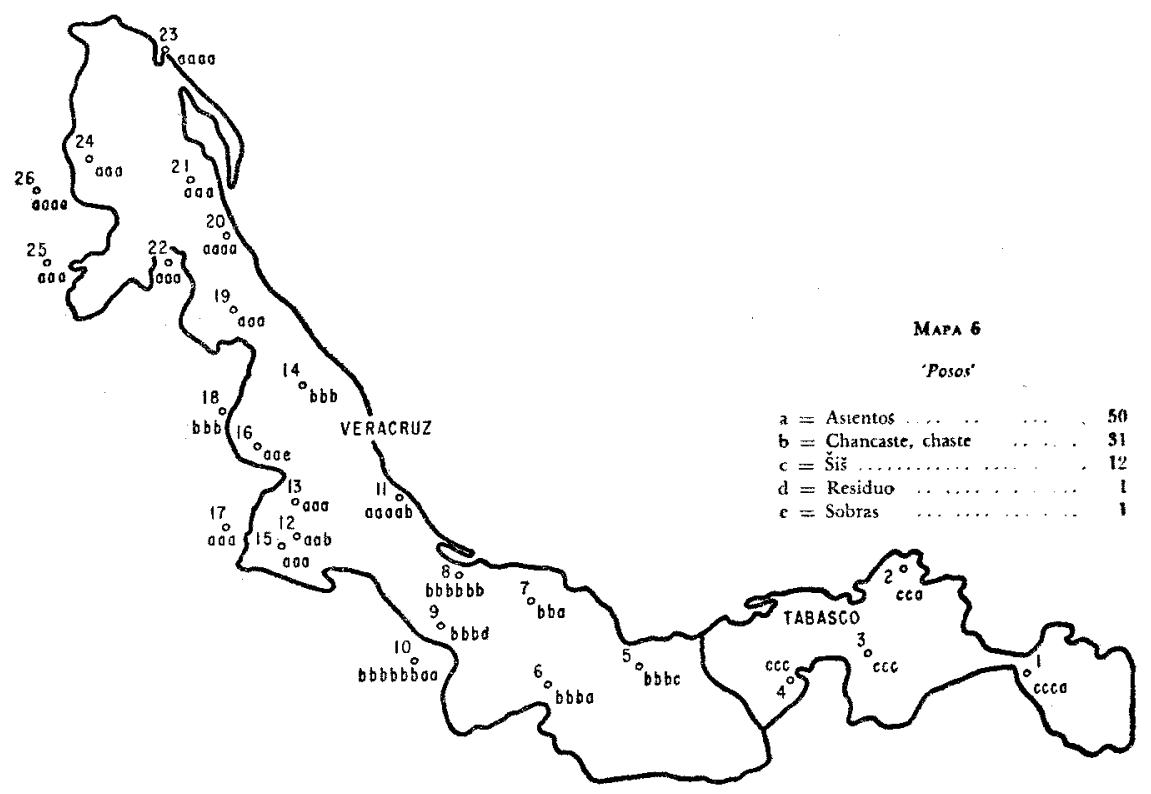

Mapa 7. 'Pavo' (LZM, 8). Tarasco: de doce respuestas obtenidas, diez corresponden a pavo, variante típicamente yucateca, que sólo apareció tres veces en el estado de Veracruz. En 4, que colinda con Veracruz, aparece totol $(e) 2$ veces. Pueden verse dos zonas en el estado: a) sur (1 a 3), plenamente yucateca, con pavo; b) norte (4), veracruzana con totol( $(e)$. - Veracruz: Se pueden distinguir claramente dos zonas: a) 5 a 19: concurren las variantes totol( $(e)$ y guajolote, con preponderancia de totol $(e)$; b) 20 a 26: respuestas casi uniformes en guajolote. 


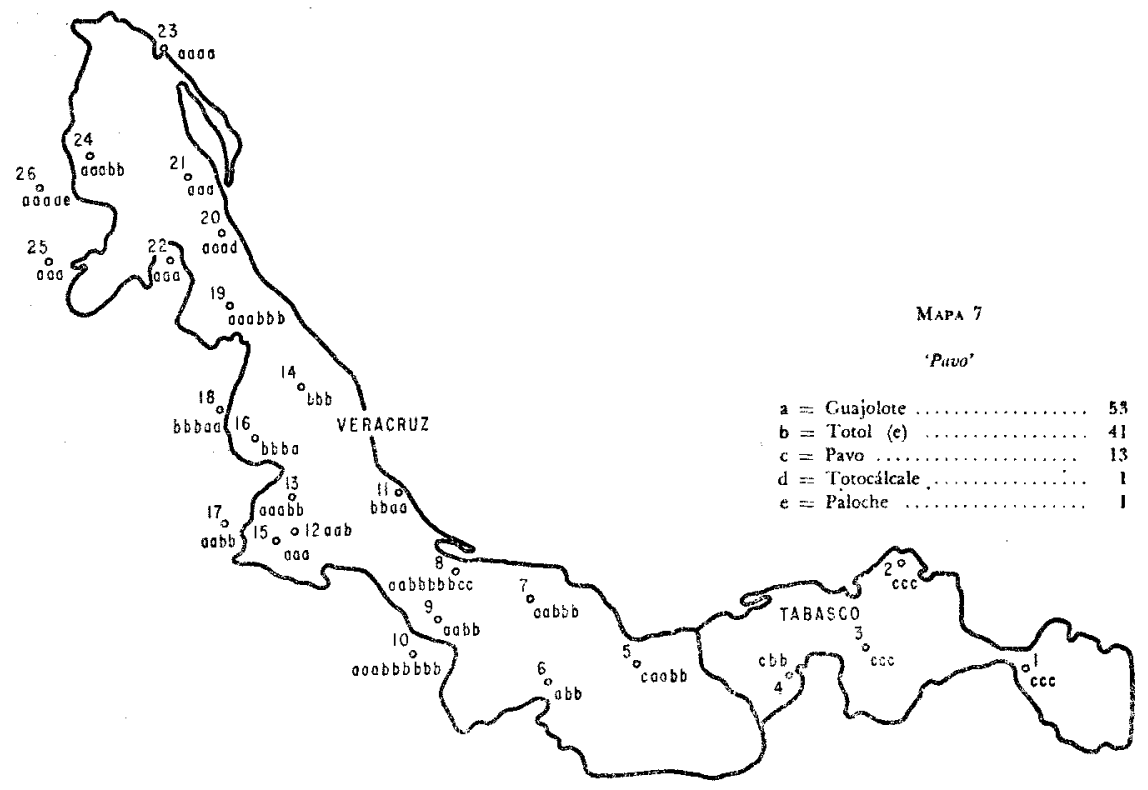

Mapa 8. 'Papalote, cometa' ( $L Z M, 9)$. TABAsco: de catorce respuestas obtenidas, cinco ( 1 y 2 ) corresponden a papagayo, variante yucateca que no se conoce en Veracruz. En la comparación de los demás puntos el resultado fue polimórfico; hubo, sin embargo, homogeneidad en las respuestas de cada lugar en particular: en 3 hubo respuesta uniforme cometa; en 4, paloma. Pueden verse tres zonas: a) sur (1 y 2), yucateca con papagayo: b) centro (3): cometa; c) norte (4): paloma. - Vera-

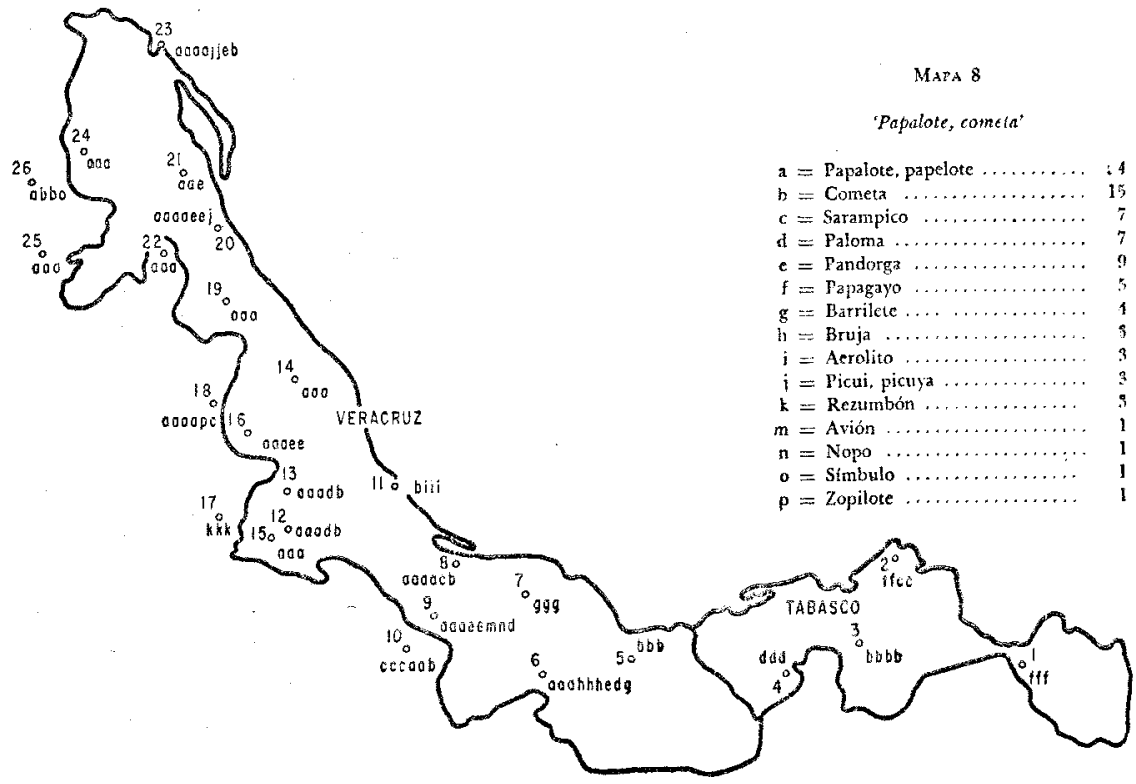


CRUz: El mapa señala dos posibles zonas: a) 5 a 11: gran polimorfismo; las localidades tienen respuestas diferentes, aunque generalmente homogéneas si se las considera aisladas. En 5 por ejemplo, sólo se documentó cometa, en 7 barrilete, en 11 aerolito (tres veces y cometa una vez); b) 12 a 26: gran uniformidad en la respuesta papalote ${ }^{7}$.

Mapa 9. 'Voltereta' $(L Z M, 10)$. TABAsco: de catorce respuestas diez corresponden a tumbacabeza, variante no documentada en Yucatán, Veracruz, o en el resto de la República; por tanto, tipifica al dialecto tabasqueño que, excepcionalmente, muestra en este concepto su individualidad. Se obtuvieron tres respuestas maroma -voz extendida prácticamente por toda la República- y sólo una volantin, que aparece también en el dialecto yucateco. Hay en el estado una sola zona casi uniforme con tumbacabeza. - VERACRUz: Se pueden distinguir dos zonas: a) 5 a 20: alternancia machincuepa-maroma, con preponderancia de machincuepa; b) 21 a 26: zona de alternancia de las mismas variantes con pleno predominio de maroma.

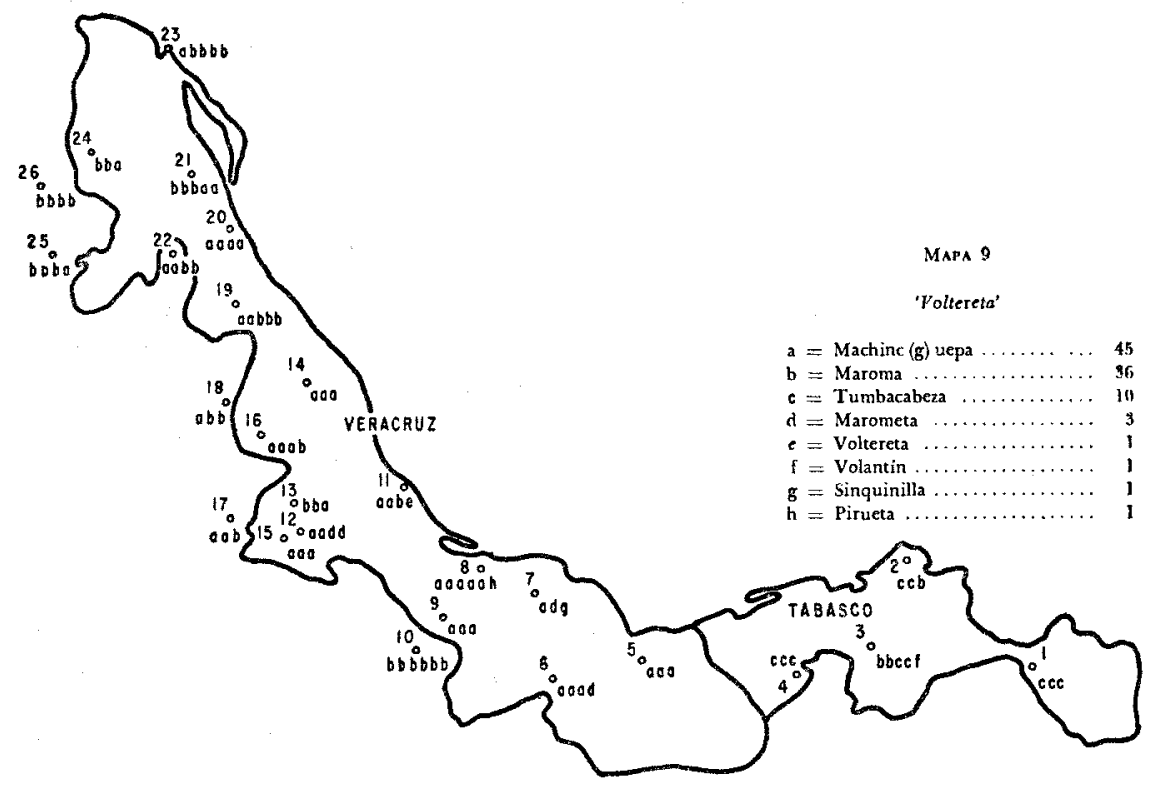

Mapa 10. 'Monedas sueltas' ( $L Z M, 12)$. TABAsco: de trece respuestas, doce corresponden a sencillo, variante característica del sureste de la República -excepto Yucatán (menudo)- que se extiende también por la parte sur del estado de Veracruz. Sólo se documentó una vez feria, voz del norte de Veracruz y, en general, de todo el norte de la República. Se observa en el estado una sola zona homogénea con sencillo.-

7 En varias localidades distinguen el nombre genérico - papalote, por ejemplode los nombres con que se designan las clases o tipos de papalote-ipandorga, palirma, etc. 
VERACRUZ: Se pueden trazar isoglosas que dividan el estado en cuatro zonas: a) 5 a 7 , predomina sencillo; b) 8 a 10: zona de gran polimorfismo con ligero predominio de feria y morralla; c) 11 a 19 , morralla; d) 20 a 26, feria.

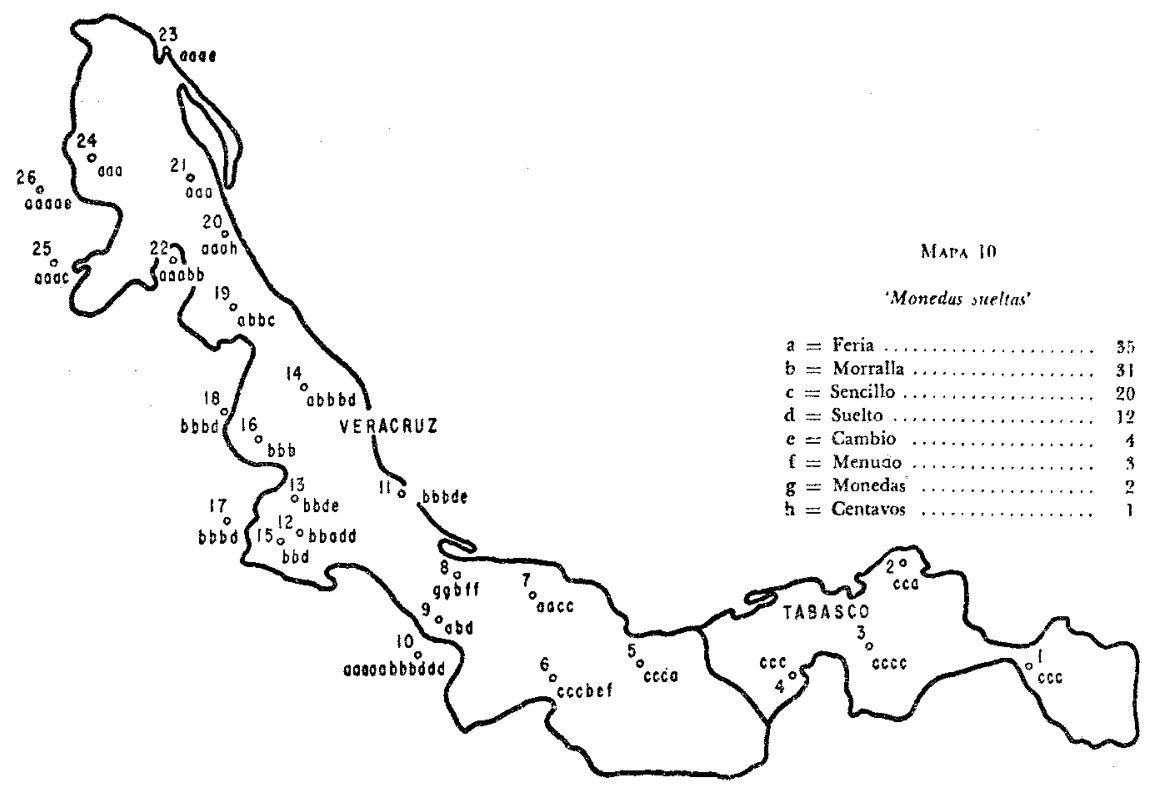

Mapa 11. 'Adehala' (LZM, 13). TABAsco: las doce respuestas correspondieron a contra, variante propia de Campeche, no de Yucatán (encima); no se documentó en Veracruz. Esta voz, en el mapa de $L Z M$, ca-

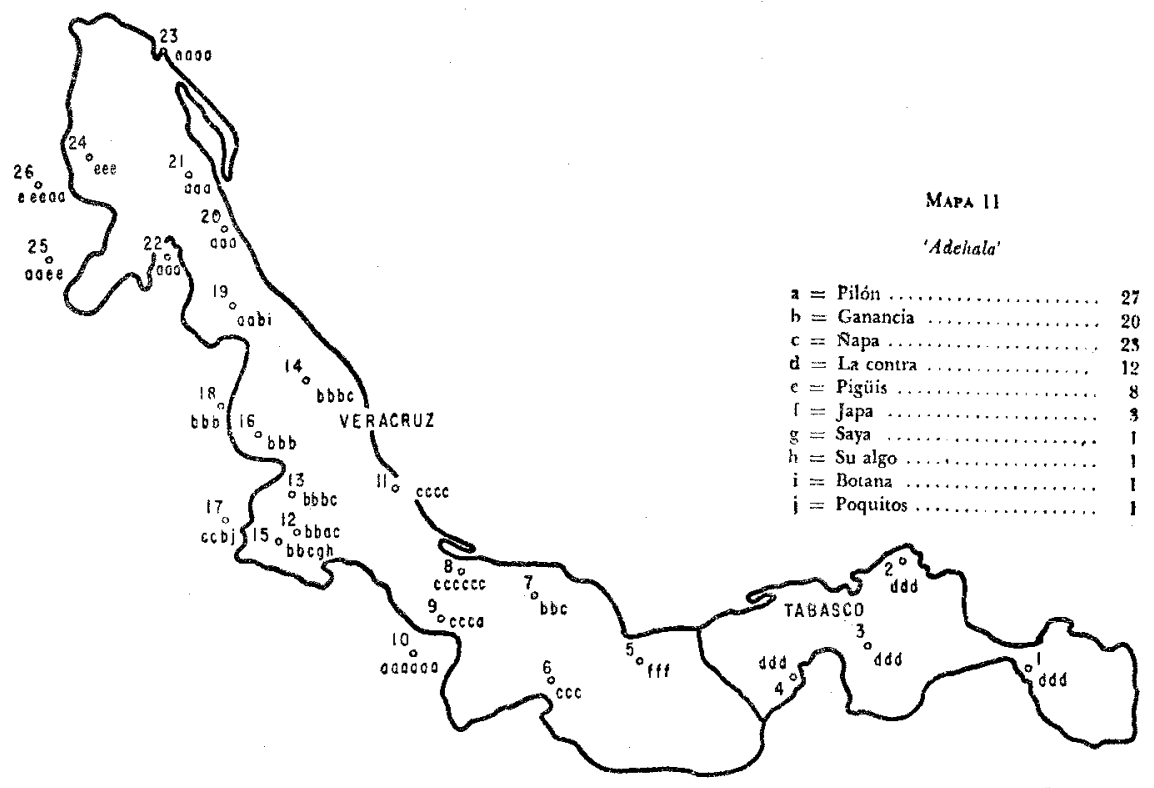


racteriza en forma exclusiva a Campeche y Tabasco, fenómeno interesante pues los dos estados se consideran frontera dialectal entre Yucatán y Veracruz ( $L Z M$, pp. 53 y 54). En Tabasco y Campeche, como he dicho, se observa una total uniformidad en contra. - VERACRUz: se pueden delimitar tres zonas, las tres de carácter polimórfico, aunque con preponderancia de alguna variante: a) 5 a 11: ñapa; b) 12 a 18: ganancia; c) 19 a 26: pilón, con la salvedad de que en los puntos 24 y 26 ocurre más frecuentemente la variante pigüis.

Mapa 12. 'Raya del pelo' ( $L Z M, 14)$. TABAsco: doce de las trece respuestas (la excepción es raya) se unifican en camino, variante que pertenece también a los estados de Campeche y Chiapas pero no a Yucatán (vereda). El término camino se documentó en cinco puntos del estado de Veracruz. - Veracruz: se pueden delimitar tres zonas: a) 5 a 7: camino; b) 8 a 18: raya; c) 19 a 26: partido, partidura. La zona b) es notablemente homogénea; las zonas a) y $c$ ) son polimórficas aunque en poca medida.

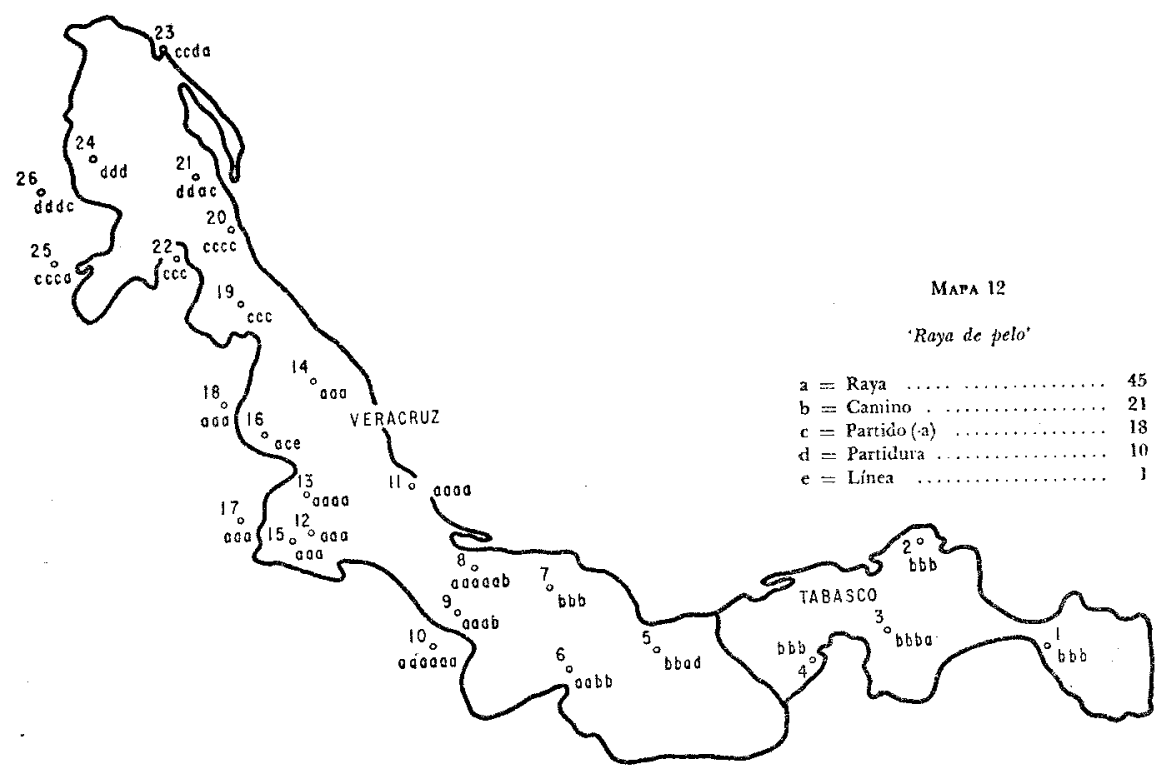

Mapa 13. 'Colibrí' (LZM, 16). Tabasco: de quince respuestas dadas, nueve corresponden a chupito, voz no documentada en ninguna otra parte de la República. En 1 los tres informantes contestaron burrión, variante sólo documentada una vez en Tapachula, Chiapas (LZM, nota 139, p. 39). Dos zonas: a) sur, 1: burrión; b) 2 a 4 (zona norte) : chupito.-VERACRUz: hay tres zonas bastante homogéneas: a) 5 a 9: chupamiel; b) 11 a 18: chupamirto; c) 19 a 26: chuparrosa. En 10, que no pertenece a Veracruz, se documentó sólo chuparrosa, en zona de evidente preponderancia de chupamiel. 


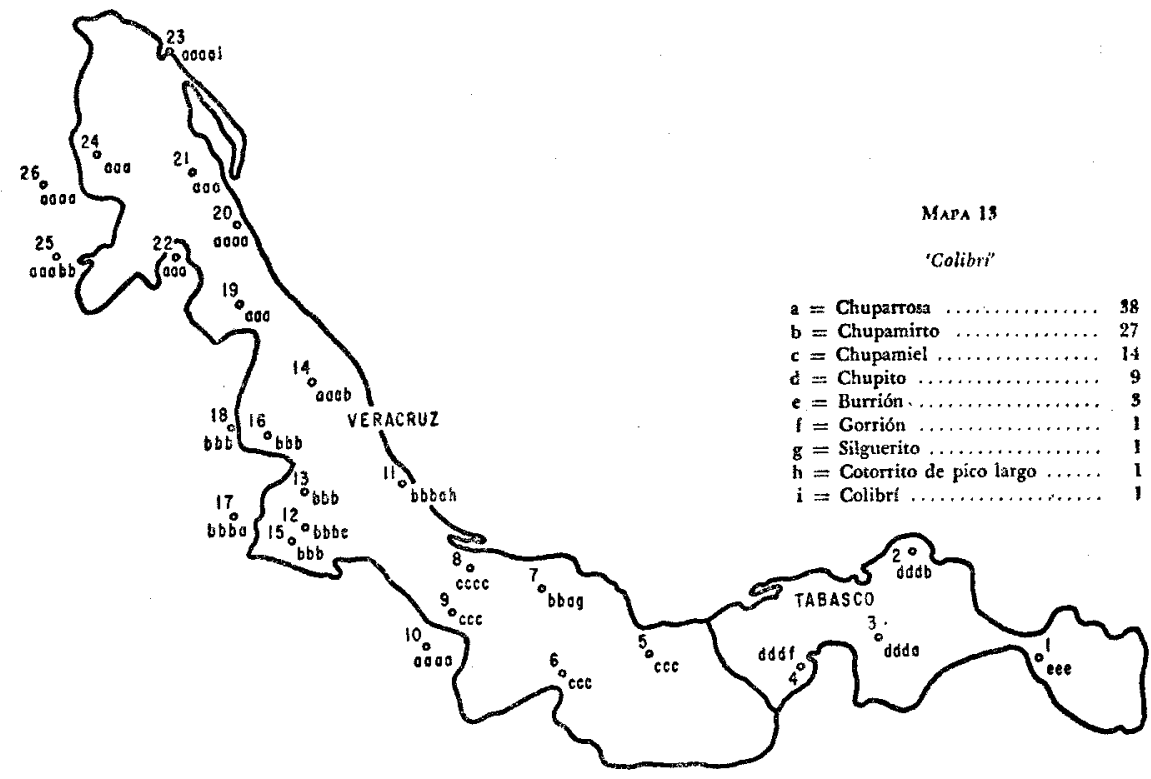

Mapa 14. 'Armónica' (LZM, 17). TABAsco: todas las respuestas, menos una (armónica), correspondieron a la variante flauta, que se extiende hasta la mitad del estado de Veracruz. Esta voz no está documentada ni en Yucatán ni en Campeche, que registran filarmónica. O bien el término es tabasqueño extendido a Veracruz, o veracruzano extendido a Tabasco. Sin embargo, no parecen satisfactorias ni una ni otra hipóte-

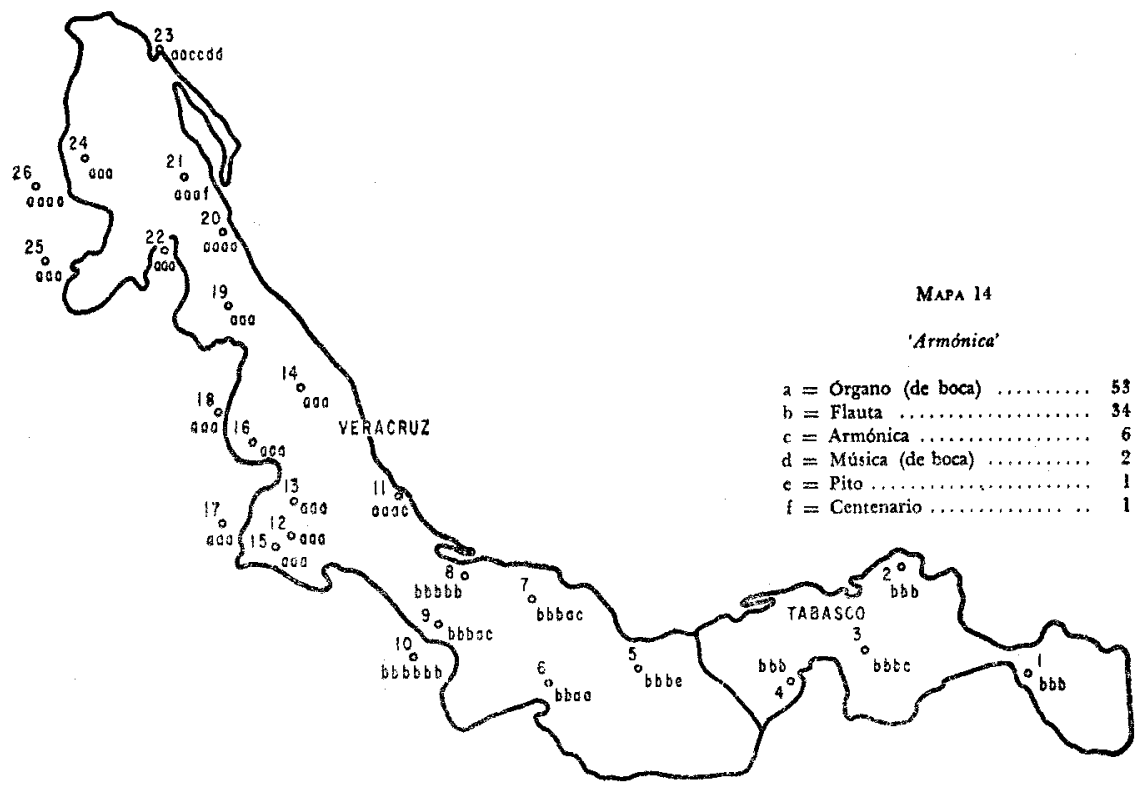


sis, pues el término flauta tiene una gran dispersión geográfica a lo largo de la costa pacífica del país. Todo el estado es una sola zona uniforme en flauta. - VerACRUz: Se distinguen dos zonas con bastante claridad: a) 5 a 10: flauta; b) 11 a 26: órgano.

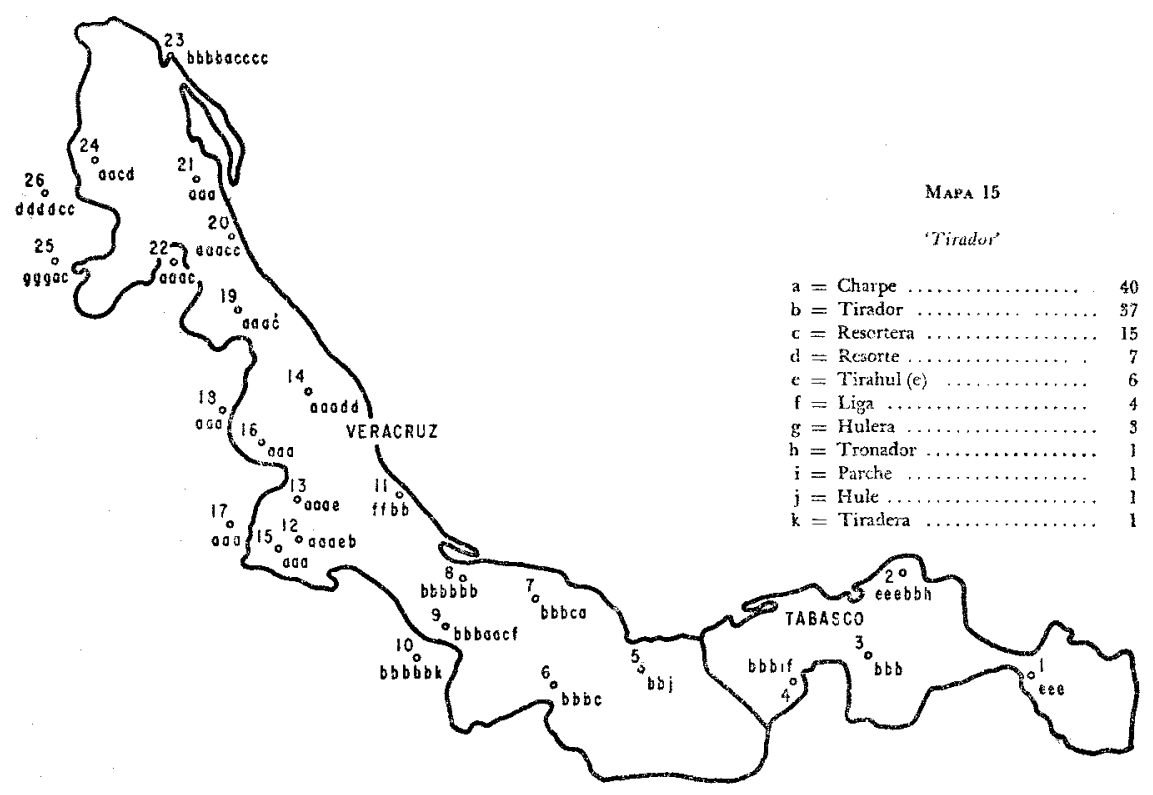

Mapa 15. 'Tirador' (LZM, 18). TABAsco: hubo diecisiete respuestas; ocho correspondieron a tirador, variante característica del sur de Veracruz; seis a tirahule, término propio de Yucatán y Campeche; una a tronador (¿confusión con tirador?), una a parche y una a liga. Es obvio que en este estado, por lo que respecta a este concepto, hay una típica zona de frontera entre el dialecto yucateco-campechano y el veracruzano. Pueden señalarse dos zonas: a) 1 (sur) : tirahule; b) 2 a 4: polimórfica con predominio de tirador. - VERACRuz: se pueden apreciar dos zonas: a) 5 a 10: tirador; b) 11 a 26 , zona polimórfica con predominio de la variante charpe.

Mapa 16. Desportillar' ( $L Z M, 20)$. TABAsco: la variante lascar, con seis apariciones, inclina el dialecto tabasqueño hacia Yucatán y Campeche; es voz totalmente desconocida en Veracruz. Las otras variantes: descascarar (cuatro apariciones) y pelar (también cuatro), contribuyen a dar carácter polimórfico a los resultados. Hay una sola zona polimórfica con predominio de lascar. - Veracruz: a lo largo del estado predomina despostillar; sin embargo, se pueden distinguir dos zonas: a) 5 a 11: polimorfismo con predominio, superior al 50\%, de despostillar; b) 12 a 26: polimorfismo con predominio, superior al $80 \%$, del mismo término. 


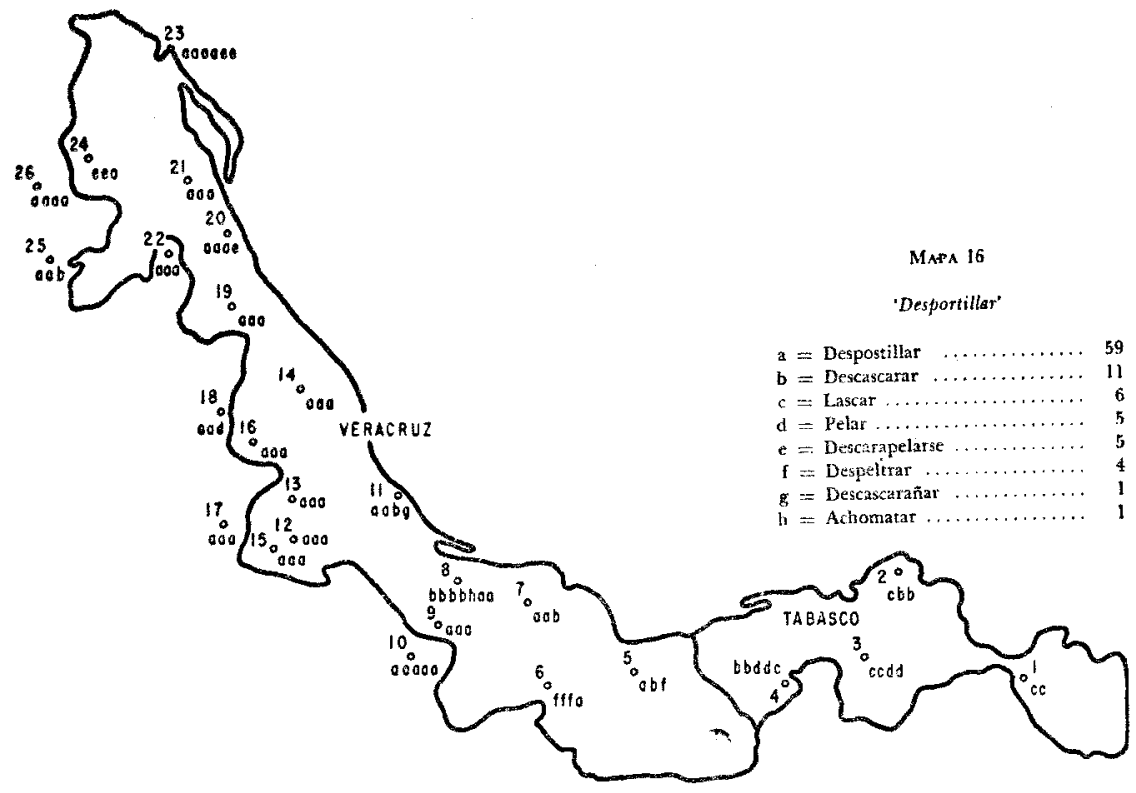

Mapa 17. 'Hilo' (LZM, 22). TABAsco: de quince respuestas logradas, doce correspondieron a hilera, característica y exclusiva del dialecto yucateco-campechano. Las tres respuestas restantes correspondieron a hilo, término general en Veracruz y en el país. Por tanto, en este concepto, Tabasco se muestra definitivamente inclinado hacia Yucatán. Hay una

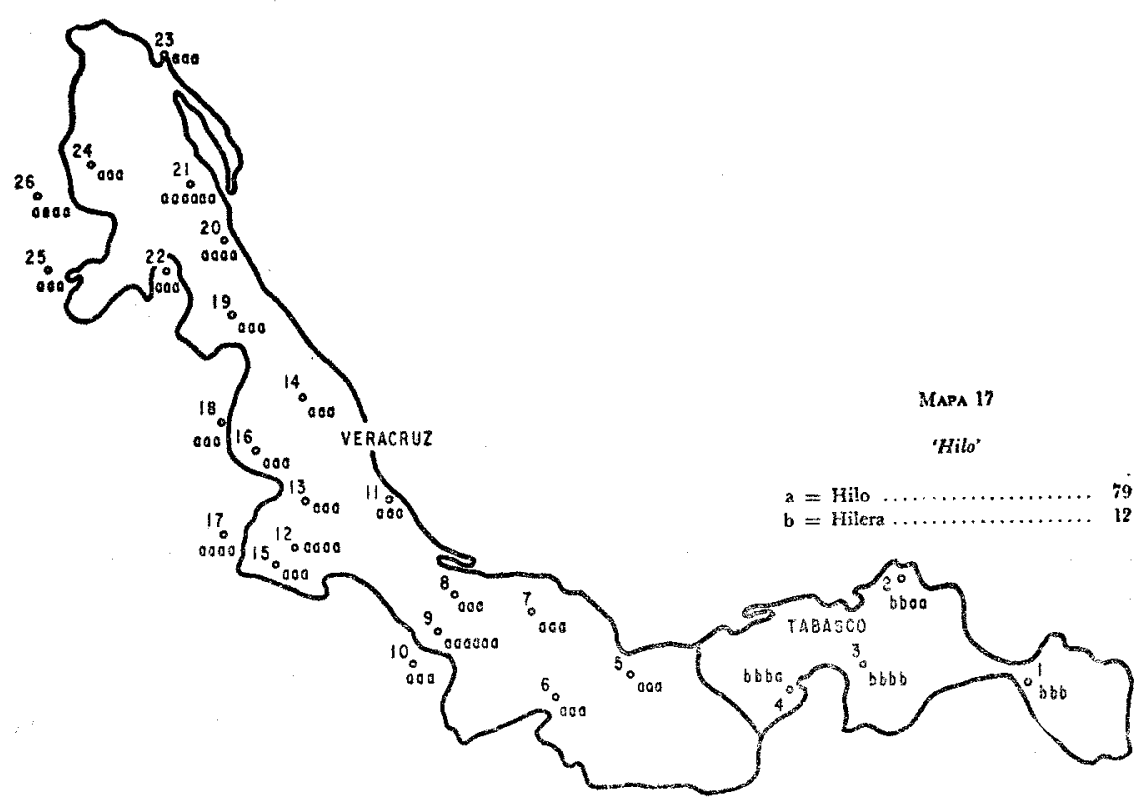


zona, con dos variantes - hilera e hilo- pero con gran preponderancia de hilera $(80 \%)$. - VERACRUz: todas las respuestas (setenta y seis) se unifican en hilo.

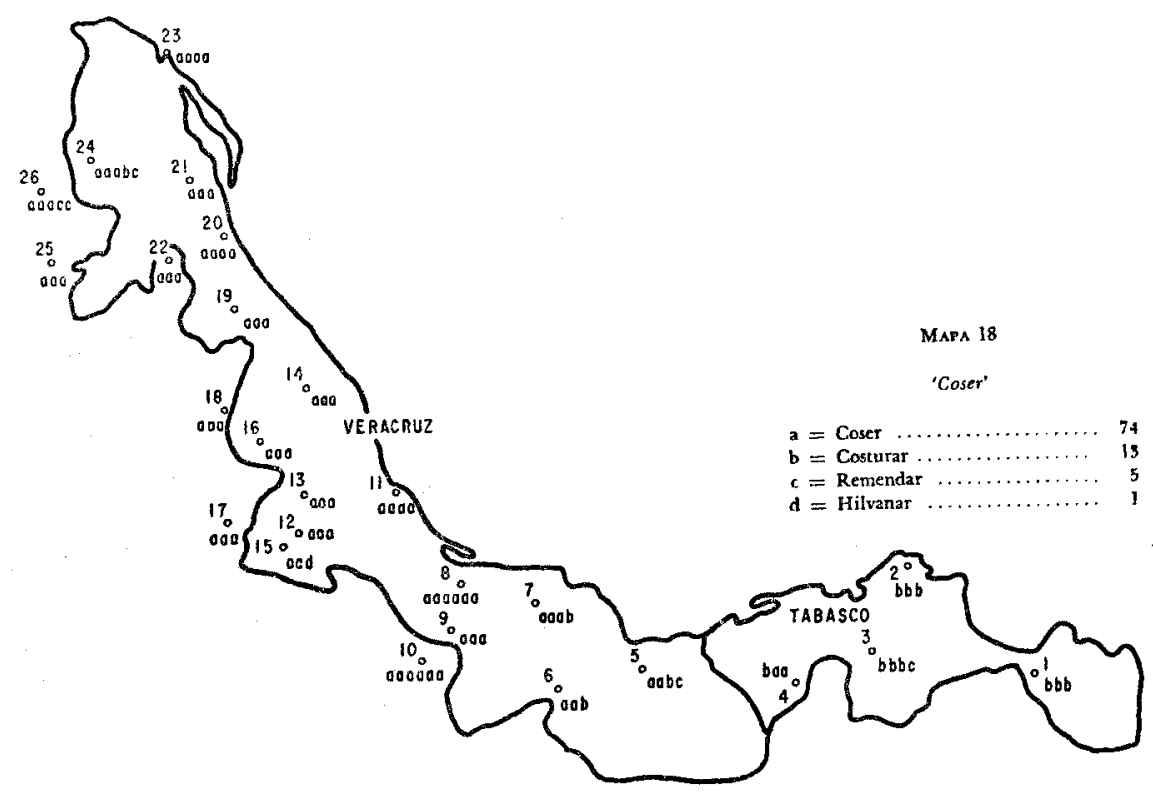

Mapa 18 'Coser' ( $L Z M, 23)$. TABAsco: hubo trece respuestas y de ellas diez fueron costurar, que pertenece al dialecto yucateco, documentado sólo tres veces en el sur de Veracruz. Se ve por tanto un paralelismo de distribución con respecto al concepto hilo (cf. mapa 17). Dos zonas: a) 1 a 3: costurar; b) 4: coser y costurar. -- Veracruz: fuera de una tímida incursión en el sur de la variante yucateca costurar (5 a 7), y de esporádicas respuestas hilvanar y remendar ${ }^{8}$, todos los informantes respondieron coser, término general en todo el país.

Mapa 19. 'Pasador' (LZM, 24). Tabasco: con excepción de una respuesta (pasador), todas las demás fueron invisible, voz típicamente yucateca, no documentada en Veracruz. Por lo tanto, puede hablarse de una sola zona: invisible. - VERACRUz: todo el estado muestra gran uniformidad en la respuesta pasador, muy generalizada en el centro de la República. Hay pues, una zona: pasador.

8 Respuestas que pueden interpretarse no como variantes léxicas de coser, sino como conceptos distintos. 


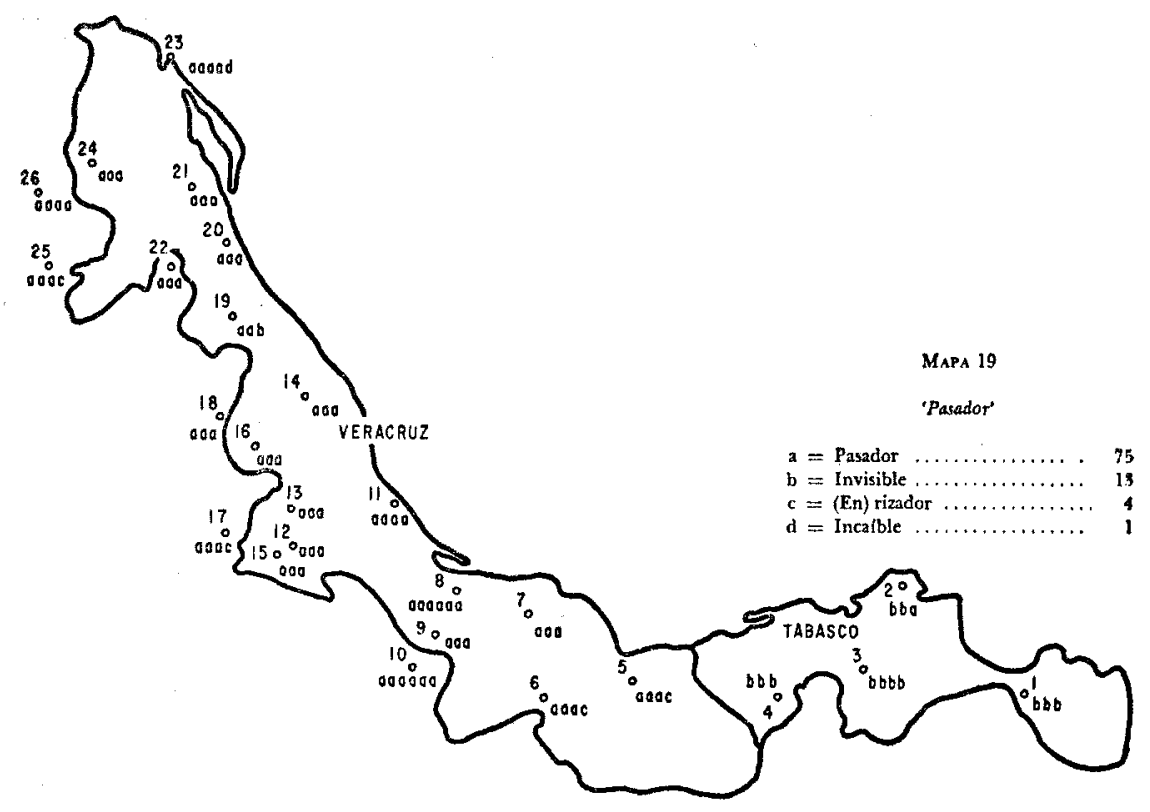

Mapa 20. 'Bíceps' ( $L Z M, 25)$. TABAsco: de quince respuestas, doce correspondieron a la variante yucateca gato(-illo), voz desconocida en Veracruz, que sin embargo es frecuente en el noroeste de la República. En Tabasco no hubo ninguna respuesta de las comunes en el estado de

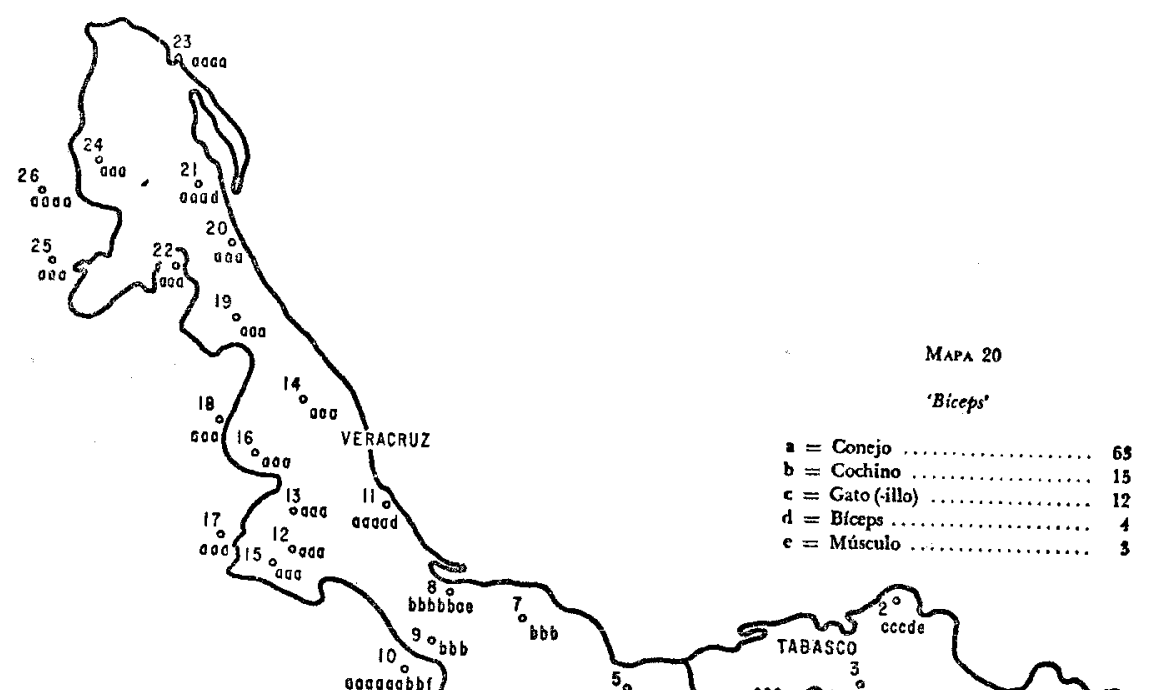


Veracruz. Se trata, de nuevo, de una sola zona: gato(-illo). - Veracruz: pueden distinguirse dos zonas: a) 5 a 10: zona de concurrencia de conejo y cochino, con preponderancia de cochino; b) 11 a 26: casi absoluta uniformidad en conejo.

\section{CARÁcter Fronterizo del dialecto tabasqueño}

Atendiendo al material estudiado, el estado de Tabasco presenta peculiaridades de dialecto fronterizo, pero con gran inclinación hacia el dialecto yucateco-campechano más que al veracruzano.

Teniendo en cuenta la variante predominante en cada uno de los mapas, pueden formarse los siguientes grupos:

I) Voces pertenecientes al dialecto yucateco-campechano: $52.6 \%$. a) siš ('migas') : m. 3 ; b) tutupiche ('orzuelo') : m. 4; c) šis ('posos') : m. 6; d) pavo ('pavo') : m. 7; e) papagayo ('papalote') : m. 8; f) lascar ('desportillar') : m. 16; g) hilera ('hilo') : m. 17; h) costurar ('coser'): m. 18; i) invisible ('pasador'): m. 19; j) gato ('bíceps') : m. 20.

II) Voces pertenecientes al dialecto campechano (no documentadas en Yucatán ni en Veracruz) : $10.5 \%$.

a) suto ('benjamín'): m. 2 ; b) contra ('adehala') : m. 11 .

III) Voces pertenecientes al dialecto campechano (documentadas también en Veracruz) : $10.5 \%$.

a) sencillo ('monedas sueltas'): $\mathrm{m} .10 ;$ b) camino ('raya del pelo'), m. 12.

IV) Voces pertenecientes al dialecto veracruzano: $15.7 \%$.

a) comido de luna ('leporino'): m. 5; b) flauta ('armónica') : m. 14; c) tirador ('tirador'): m. 15.

V) Voces documentadas sólo en Tabasco: $10.5 \%$.

a) tumbacabeza ('voltereta'): m. 9; b) chupito ('colibrí'): m. 13 .

En resumen: I, voces yucateco-campechano-tabasqueñas: $10 \quad(52.6 \%)$; II, voces campechano-tabasqueñas: $2(10.5 \%)$; III, voces campechanoveracruzano-tabasqueñas: $2(10.5 \%)$; IV, voces veracruzano-tabasqueñas: $3(15.7 \%)$; V, voces tabasqueñas: $2(10.5 \%)$. Los grupos I, II y III hacen pensar en que el dialecto tabasqueño, en cuanto a estos concep. tos, se inclina decididamente hacia la modalidad yucateco-campechana.

Zonas dialectales del estado de Tabasco. Tal vez debido al escaso número de datos que manejo en este trabajo, no resulta fácil encontrar zonas dialectales nútidas en el estado de Tabasco, pues de diecinueve mapas, sólo seis presentan división, y de éstos sólo son zonas iguales las que se observan en los mapas 5, 13 y 15: zona a) 1 ; zona b) 2-4. Los demás mapas muestran divisiones diferentes. En los mapas 9 y 18 se observa una zona a) 1-3; y zona b) 4 . El mapa 8 muestra una zona a) I y 2 y una $b$ ) puntos 3 y 4 . Todos los demás mapas muestran una sola 
zona más o menos uniforme. En todo caso, puede aceptarse que el punto I presenta un mayor grado de asimilación al dialecto yucateco-campechano que los demás puntos del estado.

Zonas dialectales del estado de Veracruz. Hay que hacer hincapié en que casi ninguna variante típicamente yucateco-campechano-tabasqueña entró en el estado de Veracruz. De esto se deduce que la frontera entre estos dos importantes dialectos -el yucateco y el veracruzano- debe buscarse precisamente en el estado de Tabasco.

Resulta sobremanera difícil establecer con cierta precisión las posibles zonas dialectales del estado de Veracruz. La observación de los mapas lleva al siguiente resumen: I. Seis mapas muestran una sola zona $(2,4,5,17,18$ y 19). - II. Siete, dos zonas $(7,8,9,14,15,16$ y 20). III. Tres mapas muestran tres zonas (11, 12 y I3). - IV. Dos mapas muestran cuatro zonas ( 8 y 10 ) . - V. Un mapa muestra cinco zonas (3). La división en dos zonas está apoyada por una relativa mayoría de mapas (siete); sin embargo esa división presenta serias dificultades pues esas dos zonas no son siempre las mismas en los siete mapas: en el mapa 7, las zonas son: a) 5 a 19 ; b) 20 a 26 . En el mapa 8: a) 5 a 11 ; b) 12 a 26. En el mapa 9: a) 5 a 20; b) 21 a 26. En el 14: a) 5 a 10; b) il a 26. En el 15: a) 5 a 10 ; b) 11 a 26. En el 16: a) 5 a 11 ; b) 12 a 26; en el 20: a) 5 a 10 ; b) 11 a 26.

Otro procedimiento, quizá más seguro que el anterior, para encontrar zonas en el estado, es el de ver cuáles se repiten con mayor frecuencia en los mapas. Estas son: I. Puntos 5-26: tres veces; II. Puntos 5-10 u II: ocho veces; III. Puntos (11) 12-26: cinco veces; IV. Puntos 19 o 20-26: seis veces. La interpretación más convincente de este resumen, a mi juicio, sería el establecer en el estado de Veracruz, atendiendo a los materiales aquí analizados, tres zonas importantes: la zona sur (aproximadamente del punto 5 al 10); la zona centro (aproximadamente del punto 11 al I8); y la zona norte (aproximadamente del punto 19 al 26).

\section{PoLIMORFISMo}

Puede observarse en los mapas presentados un notable polimorfismo en las respuestas a la mayoría de los conceptos investigados. Ahora bien, señaladas ya las cuatro zonas en que hipotéticamente puede dividirse la región motivo de estudio (una de Tabasco y tres de Veracruz), pasaré a determinar si en alguna de ellas se siente un mayor desarrollo de polimorfismo y en qué grado. Hay varias formas de investigarlo. Una de ellas es comparar el número de variantes que de cada concepto se registró en las diferentes zonas (véase cuadro l).

9 Excepciones: šiš ('posos') : una aparición en el punto 5; pavo ('pavo') : una vez en el punto 5 y dos veces en el punto 8; costurar ('coser'): una vez en el punto 5 , una en el 6 y una en el 7. 
Guadro 1

$\begin{array}{ccccc}\text { Mapa } & \text { Tabasco } & \begin{array}{c}\text { Ver. } \\ \text { (zona sur) }\end{array} & \begin{array}{c}\text { Ver. } \\ \text { (zona } \text { centro) }\end{array} & \begin{array}{c}\text { Ver. } \\ \text { (zona }\end{array} \\ 2 & 7 & 2 & 4 & 11 \\ 3 & 3 & 4 & 8 & 5 \\ 4 & 3 & 2 & 3 & 5 \\ 5 & 4 & 7 & 7 & 7 \\ 6 & 2 & 4 & 3 & 1 \\ 7 & 2 & 3 & 2 & 4 \\ 8 & 4 & 9 & 9 & 5 \\ 9 & 3 & 5 & 4 & 2 \\ 10 & 2 & 7 & 4 & 5 \\ 11 & 1 & 4 & 6 & 4 \\ 12 & 2 & 3 & 3 & 3 \\ 13 & 5 & 4 & 4 & 4 \\ 14 & 2 & 4 & 2 & 5 \\ 15 & 5 & 6 & 5 & 3 \\ 16 & 3 & 4 & 4 & 1 \\ 17 & 2 & 1 & 1 & 3 \\ 18 & 3 & 3 & 2 & 4 \\ 19 & 2 & 2 & 2 & 2 \\ 20 & 3 & 5 & 2 & 77 \text { (Promedio: } \\ \text { TOTALES } & 58 \text { (Promedio: } & 79 \text { (Promedio: } & 75 \text { (Promedio: } & \\ & 3 \text { variantes } & 4.1 \text { variantes } & 3.9 \text { variantes } & 4 \text { variantes } \\ & \text { por concep- } & \text { por concep- } & \text { por concep- } & \text { por concep- } \\ & \text { to) } & \text { to) } & \text { to) } & \text { to) }\end{array}$

De acuerdo con este criterio, la zona mayormente polimórfica es la zona sur del estado de Veracruz, con un promedio de 4.1 variantes por concepto, seguida muy de cerca por las dos zonas restantes del mismo estado, con promedio de 4 y 3.9 variantes por concepto. La zona del estado de Tabasco sería la más homogénea, la menos polimórfica, con solamente tres variantes por concepto.

Otro sistema, que completa al anterior, es el de ver cuál es el porcentaje que en cada zona obtiene la variante más frecuente en relación con la frecuencia del resto de las variantes. Este porcentaje no siempre es inversamente proporcional al número de variantes documentado ${ }^{10}$. (Véase cuadro 2).

Aplicando este último criterio, no cabe duda de que la zona que registra el más alto grado de polimorfismo es la zona sur de Veracruz, pues el porcentaje promedio de la variante más frecuente es apenas de $65.1 \%$. La zona de más bajo índice de polimorfismo es la zona centro de Veracruz $(76.7 \%)$, seguida de la zona norte $(71.5 \%)$ y de Tabasco $(71.1 \%)$.

Varias conclusiones pueden obtenerse del cuadro precedente. El dialecto tabasqueño, a pesar de su carácter fronterizo entre el dialecto yucateco-campechano y el veracruzano, tiene un alto grado de uniformi-

10 Esto es obvio, pues aunque en una zona se documenten muchas variantes, puede suceder que sólo una de ellas sea frecuente y las demás sólo ocasionales, con lo que el indice de polimorfismo es menor de lo que haría suponer el número de variantes. 


\begin{tabular}{rlll}
\hline Mapa & \multicolumn{2}{c}{ Tabasco } \\
\hline & & & \\
& & Variante & Ptje. \\
\hline 2 & 'benjamin' & šuto & 30.7 \\
3 & 'migas' & šiš & 61.5 \\
4 & 'orzuelo' & tutupiche & 84.6 \\
5 & 'leporino' & comido de luna & 44.4 \\
6 & 'posos' & šiš & 84.6 \\
7 & 'pavo' & pavo & 83.3 \\
8 & 'papalote' & papagayo & 35.7 \\
9 & 'voltereta' & tumbacabeza & 71.4 \\
10 & 'monedas sueltas' & sencillo & 92.8 \\
11 & 'adehala' & contra & 100 \\
12 & 'raya del pelo' & camino & 92.3 \\
19 & 'colibri' & chupito & 60 \\
14 & 'armónica' & flauta & 92.3 \\
15 & 'tirador' & tirador & 47 \\
16 & 'desportillar' & lascar & 42.8 \\
17 & 'hilo' & hilera & 80 \\
18 & 'coser' & costurar & 76.9 \\
19 & 'pasador' & invisiblc & 92.3 \\
20 & 'biceps' & gato & 80 \\
& & & 71.1 \\
Porcentajc promedio: & & \\
& & & \\
\hline
\end{tabular}


dad en sus variantes, que, por otra parte, son casi siempre diferentes de las variantes de las zonas veracruzanas ${ }^{11}$, tanto en las denominaciones de base indígena, como en las de base hispánica ${ }^{12}$.

En la zona sur del estado de Veracruz, la más polimórfica, aún no se percibe perfectamente definido el dialecto propiamente veracruzano, que, en cambio, está nítidamente individualizado en la zona centro, la zona más homogénea. El dialecto veracruzano parece estar teñido en el sur por el dialecto tabasqueño y en el norte quizá por el dialecto tamaulipeco. Para siete de los diecinueve conceptos se registró una misma variante como más frecuente en las tres zonas de Veracruz; para seis conceptos se registró la misma variante en la zona centro y la zona norte; para tres conceptos la misma variante fue documentada en la zona sur y la zona centro; para dos conceptos se documentaron diferentes variantes en cada zona; finalmente, para un concepto una misma variante se documentó en la zona sur y norte y no en la zona centro. Esto me lleva a pensar que hay más cohesión entre la zona centro y la zona norte, que entre la zona centro y la sur. También desde este punto de vista la zona sur se nota más alejada del foco del dialecto, que vendría a ser la zona centro. En otras palabras, si se acepta que, dadas ciertas zonas dialectales, algunas de ellas pueden considerarse focos de irradiación lingüística más importantes alrededor de los cuales giran otras zonas dialectales de menor importancia, podría pensarse que la zona yucateca sería un foco dialectal que influye en las zonas de Campeche y Tabasco. Otro foco sería la zona centro del estado de Veracruz, que irradia influencia lingüística en las zonas sur y norte del mismo estado. En Ia misma forma en que el dialecto campechano recibe mayor influencia del foco dialectal yucateco que el dialecto tabasqueño, así, en la zona norte de Veracruz influye, más que en la zona sur, el foco dialectal importante, situado en la zona centro ${ }^{13}$. De lo expuesto arriba concluyo que:

a) El dialecto del estado de Tabasco es ciertamente, como había notado Lope Blanch ${ }^{14}$, un dialecto fronterizo entre el yucateco-campechano y el veracruzano, pero, según los materiales aquí analizados, inclinado notablemente hacia el yucateco-campechano.

b) No parecen percibirse zonas dialectales dentro de Tabasco, aunque cabe mencionar que el sur del estado, como es de esperarse, está más teñido de dialectalismos yucateco-campechanos que el resto del estado. c) En el estado de Veracruz se distinguen, con mayor o menor nitidez, tres zonas dialectales: la zona sur (de Minatitlán a Tlacotalpan, puntos

11 De veintiún conceptos, sólo dos variantes predominantes se repiten en la zona sur de Veracruz: flauta (mapa 15) y tirador (mapa 16).

12 "Más reveladores [.. T serán los casos en que las denominaciones de las distintas zonas tengan bases hispánicas, y muestren oposición entre la forma yucateca y las restantes" (LZM, p. 3).

13 Es interesante destacar que precisamente en la zona centro se encuentran, entre otras ciudades importantes, el Puerto de Veracruz, principal centro de población del estado, Jalapa, capital del mismo, Córdoba, Orizaba, etc.

14 "El estado de Tabasco, por su prte, se nos muestra como una clara zona de transición lingüística, intermedia entre la yucateco-campechana y la veracruzana meridional, pero con personalidad propia" (LZM, p. 54) . 
5 a 10 ), la zona centro (del Puerto de Veracruz a Misantla, puntos 11 a 18), y la zona norte (de Papantla a Tempoal, puntos 19 a 26).

d) De las tres zonas del estado de Veracruz, puede considerarse a la zona centro la más homogénea y, a la vez, el foco lingüístico irradiador con respecto a las otras dos, que presentan mayor grado de polimorfismo ${ }^{15}$.

Universidad Nacional de México.

José G. Moreno de Alba El Colegio de México.

\section{EN TORNO A LA CENSURA DE LA LOCURA HUMANA $Y$ EXCELENCIAS DELLA DE JERÓNIMO DE MONDRAGÓN}

Para Rainundo Lida, maestro y amigo.

En 1598 el jurisconsulto aragonés Jerónimo de Mondragón ${ }^{1}$ publicó en Lérida su Censura de la locura humana y excelencias della, obra muy curiosa para la historia del movimiento erasmista en España y, según Antonio Vilanova, fuente probable de Cervantes ${ }^{2}$. No cabe duda que el Moriae encomium de Erasmo inspiró directamente la Censura ${ }^{3}$, ya que Mondragón no sólo menciona a Erasmo en el tercer capítulo ${ }^{4}$, sino que traduce e imita varios pasajes del humanista holandés.

EI Encomium y otras obras de Erasmo quedaron en el Indice español de $1559^{5}$. Por consiguiente, Bataillon ve la influencia erasmiana en España después de esa fecha como una huella subterránea, un caso de "erasmismo sin Erasmo"'. No menciona a Mondragón en su Erasmo y España, aunque la Censura sea una prueba del influjo persistente y directo del Encomium unos cuarenta años después de su condena. Y, en efecto, como señala Vilanova, era materialmente imposible destruir todos los ejemplares existentes ${ }^{7}$. Este hecho se hace aún más significativo

15 Por lo que respecta a las localidades no pertenecientes al estado de Veracruz $-10,17,18,23,25$ y $26-$, las respuestas obtenidas en ellas hacen suponer que, en mayor o menor proporción, esas localidades pertenecen a las zonas veracruzanas delimitadas: el punto 10 a la zona sur; los puntos 17 y 18 a la zona centro; y los puntos 23 , 25 y 26 , a la zona norte.

1 Es también autor del Arte para componer en metro castellano, Zaragoza, 1593, descrito por JUAN MANUEL SÁNCHEZ en su Bibliografia aragonesa, Madrid, 1914, t. 2, p. 445, y de la Universal y artificiosa ortografia de latin, Zaragoza, 1594, descrita ibid., p. 459.

2 Jerónimo de Mondragón, Censura de la locura humana y excelencias della, edición de A. Vilanova, Barcelona, 1953, p. 14.

3 Véase también M. Bigeard, La folie et les fous littéraires en Espagne (15001650), Paris, 1972, pp. 134-139.

4 "Mas no paró en esto la locura de Hannio cartaginés (aunque Erasmo la atribuie a uno llamado Plaphón), pues..." (ed. cit., pp. 57-58).

5 F. H. Reusch, Die Indices librorum prohibitorum, Tübingen, 1886, pp. 220-221.

6 Erasmo, El Enquiridion, Madrid, 1932, prólogo de M. Bataillon, p. 84.

7 Vilanova, ed. cit., p. 21. Más recientemente Bataillon se ha ocupado de la Censura y está de acuerdo con Vilanova al rechazar "la croyance naïve que les Index 